دراسة تحليلية لأسلوب أداء قالب الدراسات عند أناتولي

\title{
كونستانتينوفيتش ليدوف
}

د. أسماء عبد الصبور محمد

أستاذ مساعد بقسم التربية الموسيقية بكلية التربية النوعية - جامعة المنيا

\section{مجلة البحوث في مجالات التربية النوعية}

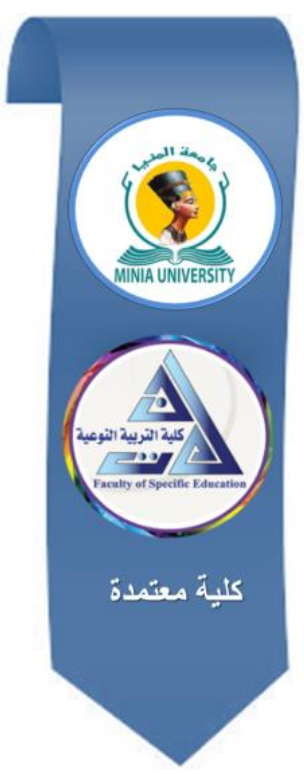

معرف البحث الرقمي DOI: 10.21608/jedu.2021.80569.1382:

$$
\text { المجلد السابع العدد } 34 \text { ـ مايو } 2021 \text { الترقيم الاولي }
$$

\section{E- ISSN: 2735-3346 P-ISSN: 1687-3424}

https://jedu.journals.ekb.eg/ موقع المجلة عبر بنك المعرفة المصري http://jrfse.minia.edu.eg/Hom موقع المجلة المون

العنوان: كلية التربية النوعية ـ جامعة المنيا ـ جمهورية مصر العربية

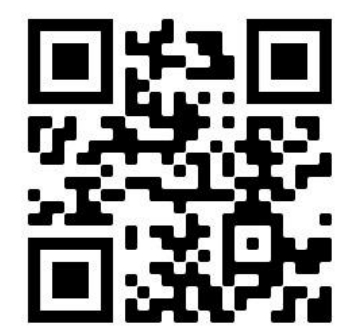


مجلة البحوث فى مجالات التربية النوعية 
دراسة تحليلية لأسلوب أداء قالب الدراسات عند أناتولي كونستانتينوفيتش ليدوف

د. أسماء عبد الصبور محمد

\section{مستخلص البحث: - 20}

بدأت الموسيقى الروسية من خلال الإنشاد الديني والترانيم الكنسية، ومع بدايات القرن الخامس عشر انتقل بعض الموسيقيون الروس للاستفادة من بعض الدول الرائدة موسيقيا

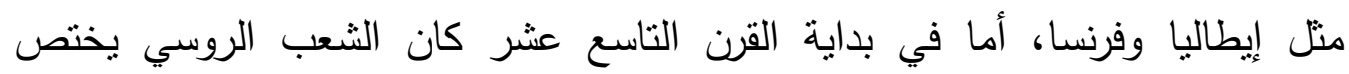
بموسيقى وألحان واناشيد واغان شعبية ورقصات فلكلورية، وفى بدايات القرن العشرين

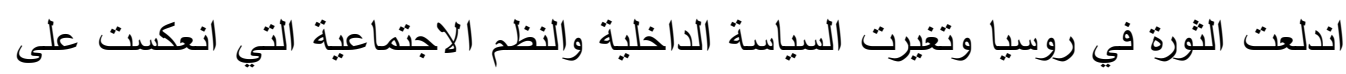
النقافة والموسيقى، وكان من الضروري ابداع موسيقى تساير المجتمع الجديد بشرط أن تكون نابعة من التقاليد والتراث الروسي، ومن أهم المؤلفين الموسيقيين الذين اشتهروا

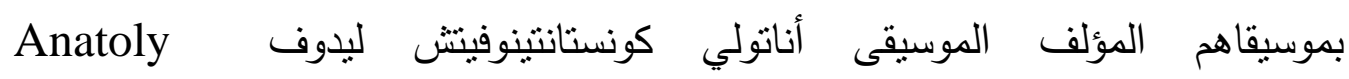
Konstantinovich Lyadov

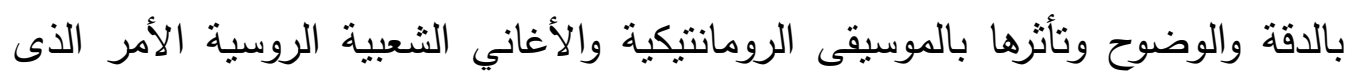
جعل الباحثة تفكر في تتاول مؤلفة (الدراسات) ذات المهارات التكنيكية بالدراسة الوصفية والتحليل وما اشتمل عليها من تحليل نظري وعزفي وذلك بهدف استخراج التقنيات العزفية التي بنيت عليها، مع وضع الارشادات اللازمة للتغلب على الصعوبات التكنيكية والعزفية وذلك للأداء الجيد، حيث جاءت ابرز النتائج أنها جاءت في صياغة هوموفونية، مع تغيير الميزان داخل القالب، وجاءت التونالية في سلم لاء كبير، كما جاءت

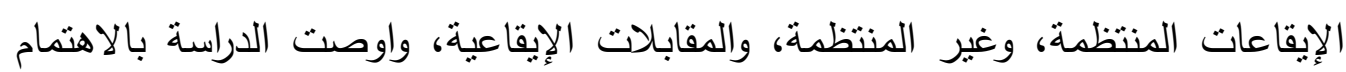
بدراسة المؤلفات الموسيقية للمؤلف الموسيقي الأمريكي أناتولي كونستانتينوفينش ليدوف الاستفادة من إدراج دراسات أناتولي كونستانتينوفيتش ليدوف في برامج تدريس آلة البيانو . لباني

\section{الكلماث الرئيسة:}

أسلوب أداء، قالب دراسات، أناتولي كونستانتينوفيتش ليدوف 
بدأت الموسيقى الروسية من خلال الإنشاد الديني والترانيم الكنسية، ومع بدايات القرن الخامس عشر انتقل بعض الموسيقيون الروس للاستفادة من بعض الدول الرائدة في الموسيقي مثل إيطاليا وفرنسا، أما في بداية القرن التاسع عشر كان الثعب الروسي يختص بموسيقى وألحان واناشيد واغان شعبية ورقصات فلكلورية، وفى بدايات القرن العثرين اندلعت الثورة في روسيا وتغيرت السياسة الداخلية والنظم الاجتماعية التي انعكست على الثقافة والموسيقى، وكان من الضروري ابداع موسيقى تساير المجتمع الجديد بشرط أن تكون نابعة من التقاليد والتراث الروسي ، وقد اعتمدت الحياة الموسيقية في روسيا على تيارين موسيقيان متميزان الأول التيار الموسيقي الأوروبي الذى تأثز بالموسيقى الفرنسية والإيطالية حيث بلغ مستوى بارزا من الإتقان وأصبح جزءا من حياة الطبقات المثقفة في روسيا، أما التيار الآخر فهو تيار موسيقى العامة وهو القائم على الموسيقى الفولكلورية والموسيقى الكنيسة الأرثوذكسية الروسية من جانب آخر، ثم تقارب هذان التياران وتفاعلا في القرن العشرين على أيدي رواد الموسيقى القومية الذين اشتهروا (1) باسم الخمسة الكبار ومـن أهـم المـؤلفين الموسـيقيين الذين اثـتهروا بموسـيقاهم المؤلـف الموسـيقى أنـاتولي - 1855) Anatoly Konstantinovich Lyadov كونستانتينوفيتش ليدوف 1914)، التي تميزت أعماله لآلة البيانو بالدقة والوضوح وتأثزها بالموسيقى الرومانتيكية والأغاني الثعبية الروسية الأمر الذى جعل الباحثة تفكر في تتاول مؤلفة (الدراسات) ذات المهارات التكنيكية بالدراسـة الوصفية والتحليل وما اشتمل عليها من تحليل نظري وعزفي واستخراج التقنيـات العزفيـة التي بنيـت عليها، مـع وضـع الارشــادات اللازمـة للتغلب على الصعوبات التكنيكية والعزفية وذللك للأداء الجيد . 


\section{مشكلة البحث:}

لاحظت الباحثة احتواء قالب الدراسات لآلة البيانو في القرن العشرين على تقنيات عزفية متعددة وأساليب منظورة في الأداء العزفى من حيث التكنيكيات والتعبيرات، ومع ذلك أيضا لاحظت الباحثة قلة تتاول دراسات القرن العشرين ضمن بنود مقرر آلة البيانو للطلاب المتخصصين، مما أدى الى اتجاه الباحثة لدراسة بعض دراسات من القرن العشربن للمؤلف الروسي أناتولي كونستانتينوفيتش ليدوف بالدراسة والتحليل العزفى وذلك للتعرف على كيفية أداء تقنياتها، والتي قد تساعد في تحسين أداء الطلاب الدارسين لآلة

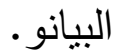

\section{أهدف البحث:} يهدف هذا البحث إلي:

1. التعرف على حياة أناتولي كونستانتينوفيتش ليدوف وأهم أعماله.

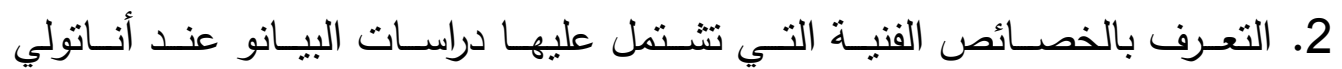
كونستانتينوفيتش ليدوف.

3. تحديد التقنيات العزفية والصعوبات التكنيكية التي تشتمل عليها دراسات البيانو عند أناتولي كونستانتينوفيتش ليدوف واسلوب معالجتها. أهمية البحث: 1. التعريف بالخصائص الفنية للقالب (عينة البحث). 2. الوصول للأداء الجيد من خلال التمارين المقترحة والارشادات العزفية. اسئلة البحث:

1. ما هي حياة المؤلف الموسيقى أناتولي كونستانتينوفيتش ليدوف وأهم أعماله؟ 2. ما هي الخصائص الفنية لدراسات البيانو عند أناتولي كونستانتينوفيتش ليدوف؟ هان 3. ما هي التقنيات العزفية والصعوبات التكنيكية التي تشتمل عليها دراسات البيانو عند أناتولي كونستانتينوفينش ليدوف واسلوب معالجتها؟ 
الحدود الزمنية: دراسات البيانو لأناتولي كونستانتينوفيتش عام (1881م).

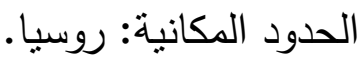

إجراءات البحث:

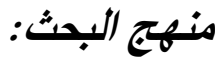

يتبع هذا البحث المنهج الوصفي (تحليل المحتوى).

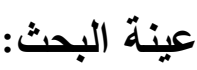

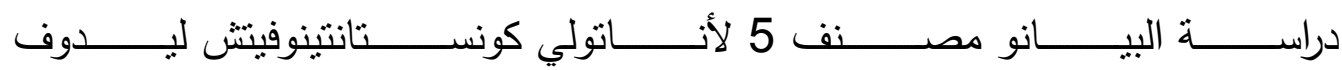

.Konstantinovich Lyadov Anatoly أدوات البحث:

المدونات الموسيقية لدراسة البيانو مصنف 5 لأناتولي كونستانتينوفيتش ليدوف

.Konstantinovich LyadovAnatoly

مصطاح البحث: - (1)

-

الدراسات Etudesهي كلمة فرنسية تعنى التدريب أو التمرين وتهدف لحل المشكلات التكنيكية لعازف البيانو، كما أطلق هنري برسيل على هذا النوع من التألبف lessons

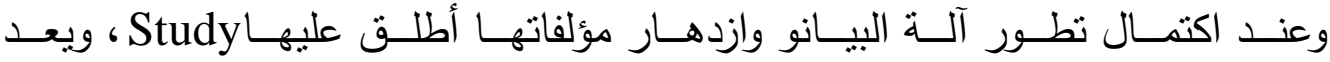
كرامر Cramerاول من أطلق عليها Etudes على هذا النوع من التأليف، أو المقطوعات الخاصة بالدراسة لتدريب الدارسين على مهارات تكنيكية مختلفة حتى أصبحت بعد ذلك مقطوعات موسيقية تحمل نفس الدارسين على مهارات تكنيكية مختلفة حتى أصبحت بعد ذللك مقطوعات موسيقية تحمل نفس المسمى. 
-Skill - المهارة - -

نشاط أدائي مركب بتطلب فترة زمنية من التدريب المقصود للممارسة المنتظمة

المضبوطة لاكتسابه وتأديته بطريقة منقنة. (1)

\section{- الصعويات التكنيكية Technique Difficulties:}

صعوبات يواجهها المتعلم أثناء دراسته المقطوعات التي لم يسبق تعلمها، والتدريب عليها، وقد تكون صعوبات تكنيكية أو تعبيرية. تقوم هذه الاراسة على قسمين: الإطار النظري: وينقسم الى اثنين: أولاً: الدراسات السابقة.

ثنانياً: نبذة عن حياة أناتولي ليدوف Anatoly Lyadov. الإطار التطبيقي وينقسم الى:

أولاً: الدراسـة التحليليـة لدراسـات البيـانو عند أنـاتولي ليـدوف، وتحديــ الصـوبات التكنيكية وتذليلها. ثانيا: نتائج البحث. أولا الاراسات السابقة المرتبطة بموضوع البحث: جـاءت الدراسـات السـابقة المرتبطـة بهذا البحث باللغـة العربيـة والاجنبيـة تتــاول قالب هـ دراسات البيانو .

الاراسة الأولى بعنوان: " اسلوب أداء دراسات البيانو عند فيروتثيو بوزوني "(3) هدفت هذه الدراسة الى التعرف على الخصائص والعناصر الموسيقية التي تحتويها دراسات البيانو بوزوني، والتعرف على الصسوبات التكنيكية الموجودة بها ومحاولة

1.Michae L Kennedy: The concise oxford dictionary of music 3 thewier. p299.

2.آمال صادق، فؤاد أبو حطب: "مناهج البحث وطرق التحليل الإحصائي"، مكتبة الأنجلو المصرية، القاهرة، 1991م، ص

3. إيمان عبد الفتاح على عثمان: "اسلوب أداء دراسات البيانو عند فيروتشيو بوزوني"، رسالة ماجستير، كلية التربية الموسيقية، جامعة

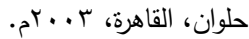


التغلب عليها، وكانت عينـة البحث أربـع دراسـات وتتفق هذه الدراسـة مـع البحث الحالي في تتاول مؤلفات الدراسات بالتحليل العزفي، وتختلف معها في عينة البحث

$$
\text { والمؤلف الموسيقي. }
$$

الاراسـة الثانيـة بعنـوان:" دراسـة الايقاعـات المركبـة في دراسـات البيـانو عنــ جـورجي

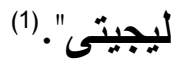

Gyorgy Ligeti's Piano Etudes, A Polyrhythmic Study

هدفت الدراسة إلى التعرف على الايقاعات المركبة في قالب دراسات البيانو عند جورجي لجيتي، والتعرف على الخصائص الفنية والأدائية للقالب ويتفق هذا البحث مع البحث الراهن في تتاول في استخدام المنهج الوصفي التحليلي وأيضا في نوع القالب عينة البحث وهي الدراسات للبيانو، ويختلف في تتاول المؤلف الموسيقى، وترجع الاستفادة من التعرض لهذا البحث إلى التعرف على اسلوب صياغة الدراسات لآلة البيانو والتوصل الي الحقائق المرتبطة بالخصائص الفنية للقالب.

الاراسة الثالثة بعنوان: " أسلوب أداء دراسات البيانو عند سكريابين "(2) هدفت هذه الدراسة الى التعرف على أسلوب أداء دراسات البيانو عند سكريابين من خلال

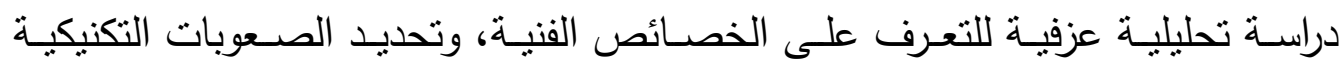
والعزفية مع تذليلها، ويتفق هذا البحث مع البحث الراهن في تتاول في استخدام المنهج الوصفي التحليلي وأيضا في نوع القالب عينة البحث وهي الدراسات للبيانو، ويختلف في تتاول المؤلف الموسيقى، وترجع الاستفادة من الدراسة الحالية التعرف على أسلوب تأليف الدراسات وخصائصها الفنية.

1. JI Won Baik:" Gyorgy Ligeti's Piano Etudes, A Polyrhythmic Study", Florida State University, College of Music, for the degree of Doctor of Mudic ،Summer Semewter, 2009

2. يونس محمود محمد بدر: " أسلوب أداء دراسات البيانو عذد سكريابين "، رسالة دكتوراة غير منشورة، كلية النربية الموسيقية، جامعة 
الدراسة الرابعة بعنوان:" الدراسات في القرن العشرين من خلال أسلوب سليم بـالمجرين

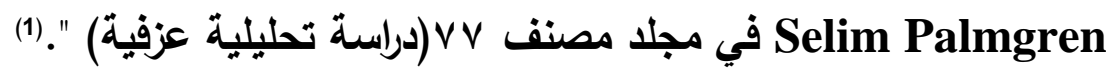
هدفت الدراسـة إلي التعرف علي التعرف علي أسلوب سليم بـالمجرين في تأليفه لمجلد رقم VVV للاسراسـات، وحياته، وأهم أعماله، وتحديد الصعوبات العزفيـة في مجلد رقي للدراسات للمؤلف الموسيقي سليم بالمجرين، ويتفق هذا البحث مـع البحث الراهن الحالي في تتاول نوع القالب وهو الدراسات، ويختلف في تناول الثخصية الموسيقية.

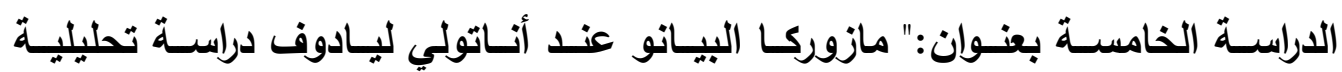

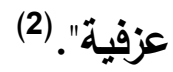
هدفت الدراسة إلى التعرف على حياة المؤلف الروسي اناتولي ليادوف وأسلوبه في التأليف وأهم مؤلفاته، وعلى الخصائص الفنية التي بشتمل عليها مازوركا البيانو عند اناتولي ليادوف، مع تحديد التقنيات العزفية والصعوبات التكنيكية التي يشتمل عليها، واسلوب معالجتها بالتمارين المقترحة والارشادات العزفية، واتبع الباحث المنهج الوصفي، ويتفق هذا البحث مع البحث الراهن في تتاول في استخدام المنهج الوصفي التحليلي وأيضا في المؤلف الموسيقى ، ويختلف في تتاول القالب ، وترجع الاستفادة من التعرض لهذا البحث إلى التعرف على حياة وأسلوب صياغة المؤلف الموسيقى لآلة البيانو والتعرف على أهم أعماله لآلة البيانو . ثنانيا الاراسات: (1)

تعتبر الدراسات من المؤلفات الآلية ذات الأهمية الكبيرة في تحسين القدرة العزفية لدى العازف وهى عادة تعالج صسوبات تقنية متتوعة تتمنثل في السـلالم و الأربيجات

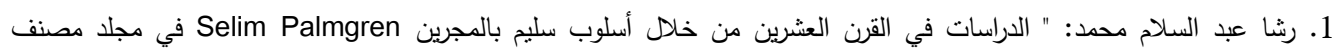

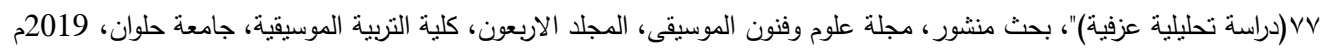

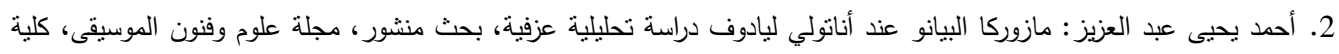
التربية الموسيقية، المجلد الواحد والاربعون، يونيو 2019 م.

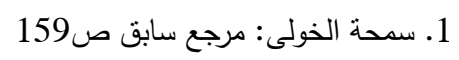

2.Thompson, Virgil: American Music Since 1910, Weidenfeld and Nicgolson, London 1971 
والنغمات المزدوجهة و الحليات وغيرها والظهور الحقيقي لدراسـات البيانو جاء في بداية القرن التاسع عشر حيث استخدم المصطلح الفرنسي Etudes الذى يعنى التمارين وذلك مـع تطور آلة البيانو وتقنيـة العزف عليها وانقسمت مؤلفة الدراسـات الى نوعين النوع الأول دراسـات للتدريب على الصعوبات التقنية والنوع الثاني دراسـات فنية تخدم التقنية الى جانب التعبير العاطفي ومن أبرز مؤلفي النوع الأول كارل تشبرني Carl Czerny (1858-1771)Johann Cramer ومن ألمانيا يوهان كرامر) (1851)

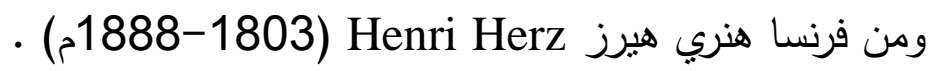
ثانياً: نبذة عن حياة أناتولي كونستانتينوفيتش ليدوف Anatoly Lyadov

\section{مولاه ونشأته واسلويه: (1)}

أناتولي ليدوف هو مؤلف موسيقى روسي وعازف بيانو ماهر ولد عام 1855 م في مدينة سانت بطرسبرج ، درس الموسيقى من الصغر على يد والده كونستانتينوفيتش ليدوف وقد لمس والده موهبه ابنة الموسيقية لذلك أرسله عام1870 م الى معهد سانت

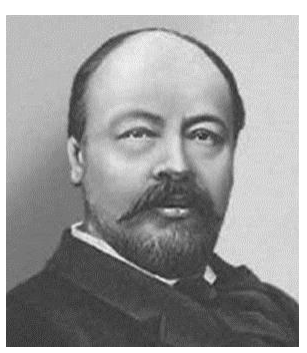
بطرسبرج ( St. Petersburg) لدراسة البيانو والكمان وقد ساعده نبوغه الموسيقى وموهبته الموسيقية الطبيعية الى تفوقه كما تأثز بالخمسة الكبار وهم سيزار كوي (César Cui)، مودست موسوركسكي(Modest Mussorgsky)، نيكولاي ريمسكى( Nikolai) (Rimsky-Korsakov)،كورساكوف، الكسندر بورودين(Alexander Borodin)، وقد تعلم الموسيقى على يد كلا من نيكولاي ريمسكى(Nikolai Rimsky)، كورساكوف(Korsakov)، وفى عام 1887 م قام بالتدريس في معهد الموسيقى الذى درس فيه وكان من بين طلابه سيرجى بروكوفيف ، وقد اشتهر عنه انه كان مدربا موسيقيا لامعا وقائدا للأوركسترا منميزا ، لذلك تم تعيينه قائدا لجمعية أوركسترا بطرسبورغ الفيلهارمونية وقائد

\section{1. https://ar.vvikipedla.com/wiki/anatoly_lyadov}


فرقة امباريل كما اثتهر بانه ناقد موسيقى متميز وقد تميز أسلوبه بالدقة والوضوح والصرامة مما أدى في الحد من انتاج اعماله ، وفى عام 1884 م قاد مجموعة من الحفلات الموسيقية عرض من خلالها السيمفونية الروسية وقد ساعد في تأسيس جائزة للتميز الموسيقى باسم جليكا وهى جائزة سنوية ، كما أسس دار للنشر عام 1885 م وذلك لنشر موسيقاه على نفقته الخاصة ، وفى عام 1887 م التقى ليدوف بتشيكوفسكى الذى اعجب بموسيقاه ونشأت بيتتهم علاقة موسيقة متباينة وفى عام 1914 م توفى بعد صراع مع المرض وبعد وفاته قام الاتحاد السوفيتي بإصدار طابع بريد بأسمة تخليدا لذكراه أسلويه:

اتسم أسلوبه بالدقة والوضوح وتأثره بالموسيقى الرومانتيكية والأغاني الثـعبية الروسية ودمجها بأسلوب مبتكر يوضح من خلاله أسلوبه المتميز في صياغة الحان موسيقاه.

\section{أهم أعماله لآلة البيانو: (1)}

- 14 مقطوعة للبيانو مصنف 2 عام1876م

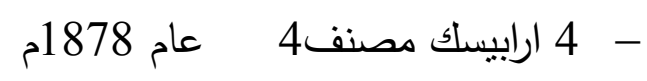
- قالب الدراسة مصنف 5 عام 1881م - 2 انترميتزو مصنف 7 مام 1881م - قالب الفالس مصنف 8 عام 1883م - 4 بريليود مصنف 13 عام 1887م

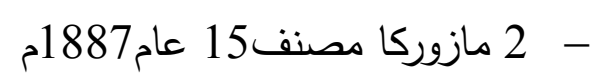

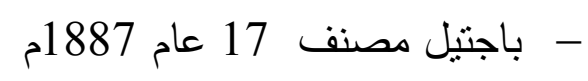

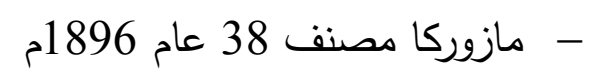

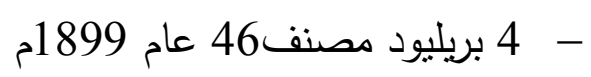
- تنويعات علي الة البيانو مصنف 51 عام 1901م - 3 قطع الباليه مصنف 52 عام 1901م

\footnotetext{
1.https://imslp.org/wiki/Category:Lyadov,_Anatoly
} 
مجلة البحوث فى مجالات التربية النوعية

$$
\begin{aligned}
& \text { - } 3 \text { باجنيل مصنف } 53 \text { عام 1903م } \\
& \text { الإطار التطبيقي: }
\end{aligned}
$$

قامت الباحثة بالتحليل النظري العزفى لعينة البحث (دراسة البيانو مصنف رقم5) أناتولي ليدوف مع تحديد الصعوبات والمشاكل التكنيكية التي تواجه دارسي آلة البيانو وكيفية التغلب عليها وذلك للوصول الى الأداء الجيد على النحو التالي:

$\underline{\text { Etude }}$

$$
\text { التسلم: لا / العبيل العام: كبير }
$$

Allegro ma non troppo السرعة: سريع باعتدال

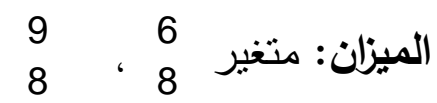

$$
\begin{aligned}
& \text { الطول البنائي: } 58 \text { مازورة } \\
& \text { النسيج: هوموفوني ـ هارموني } \\
& \text { الصيغة: ثلاثية + كودا } \\
& \text { الأقنسام الرئيسية: } \\
& \text { القسم A: من م (1): م (8) } \\
& \text { القسم B: من م (9): م (20). } \\
& \text { إعادة للقسم B: من م (21): م (32) } \\
& \text { القسم A2: من م (33): م (54) } \\
& \text { كودا Coda: من م (54) : (58) } \\
& \text { التحليل التفصيلي: }
\end{aligned}
$$


• القسم A: يعرض المؤلف فيه الفكرة الأساسية وتتكون من عبارة وتكرارها وتقوم على لحن صاعد في اليد اليمنى في سلم لا بيمول الكبير، من م (1): م (4) باستخدام النموذج الإيقاعي الأساسي مع مصاحبة باليد اليسرى على هيئة فرد نغمات التآلفات الهارمونية بالتبادل مع هارمونيات رأسية وتتتهي بقفلة تامة في سلم لا بيمول الكبير .

Max Vogrich Allegro ma non troppo

Anatole Liadoff. Op.5
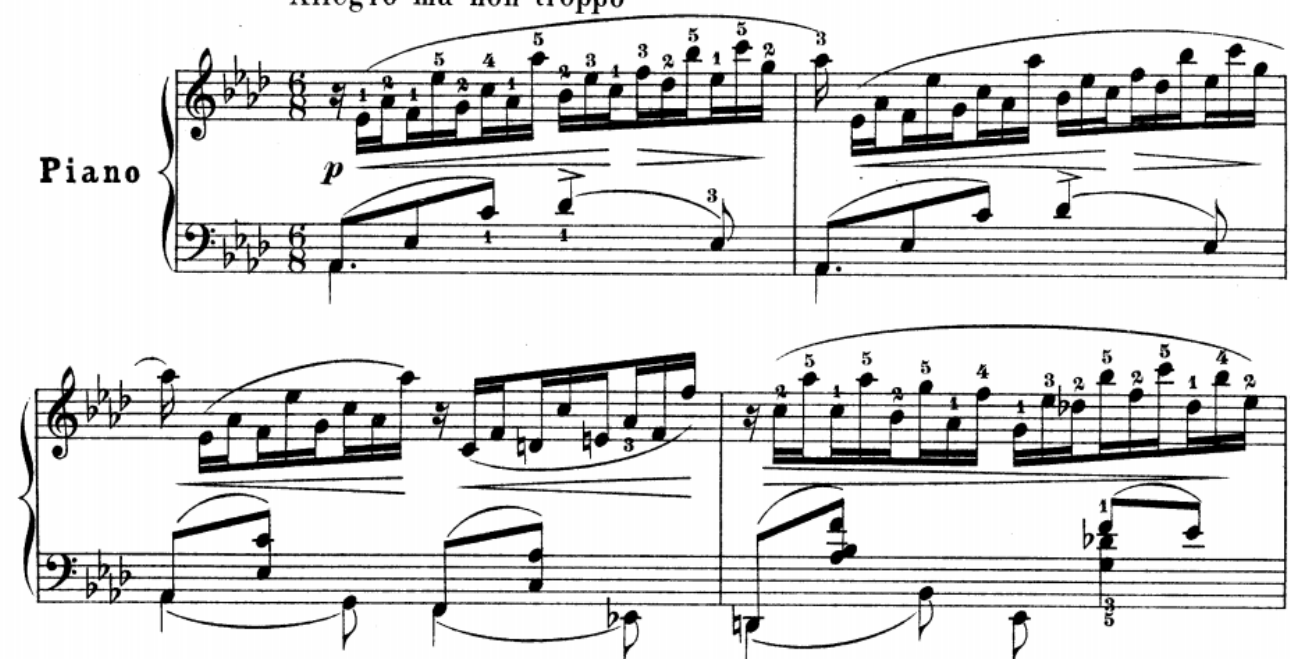

شكل رقم (1) يوضح العبارة الأولى للقسم A من من م(1): م(4)

• العبارة الثانية: من م (5): م (8) ويتم تغيير المصاحبة لتصبح على هيئة أربيجات مع تضعيف العلامات الزمنية الإيقاعية لتتنهي بقلة تامة أيضاً في سلم لان/أك. 

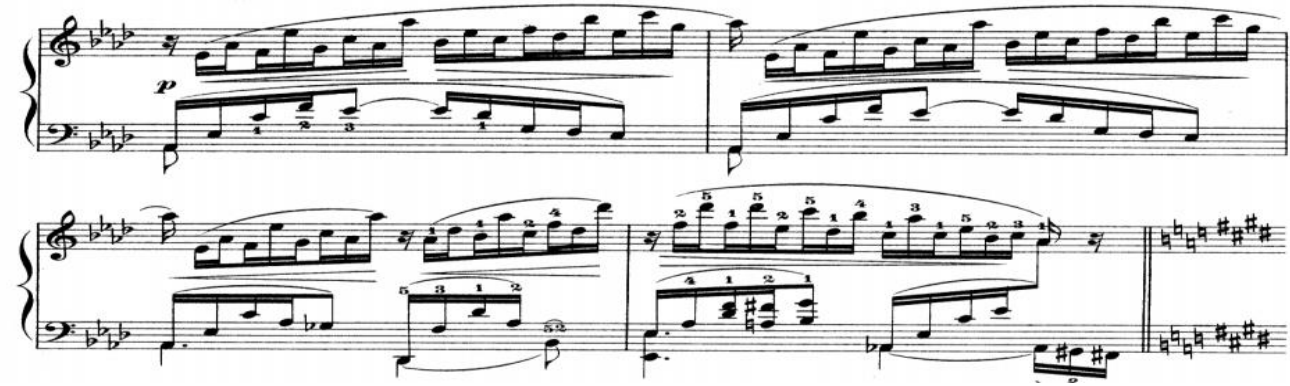

شكل رقم (2) يوضح العبارة الثانية للقسم A من من م (5): م(8)

\section{التحليل الهارموني للقسم A:}

تعتمد على مصاحبة باليد اليسرى على هيئة فرد نغمات التآلفات الهارمونية بالتبادل مع

$$
\text { هارمونيات رأسبة. }
$$

• القسم B: يتكون هذا القسم من ثلاثة أجزاء ، الجزء الأول هو عبارة من م(9) : م(12) في سلم مي/ك والققلة نامة، ويستمر المؤلف في اعتماده على نفس النموذج

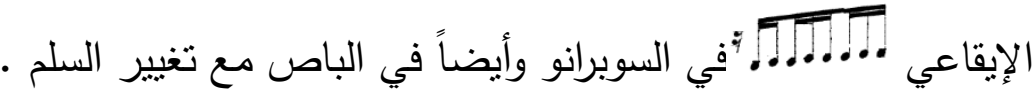
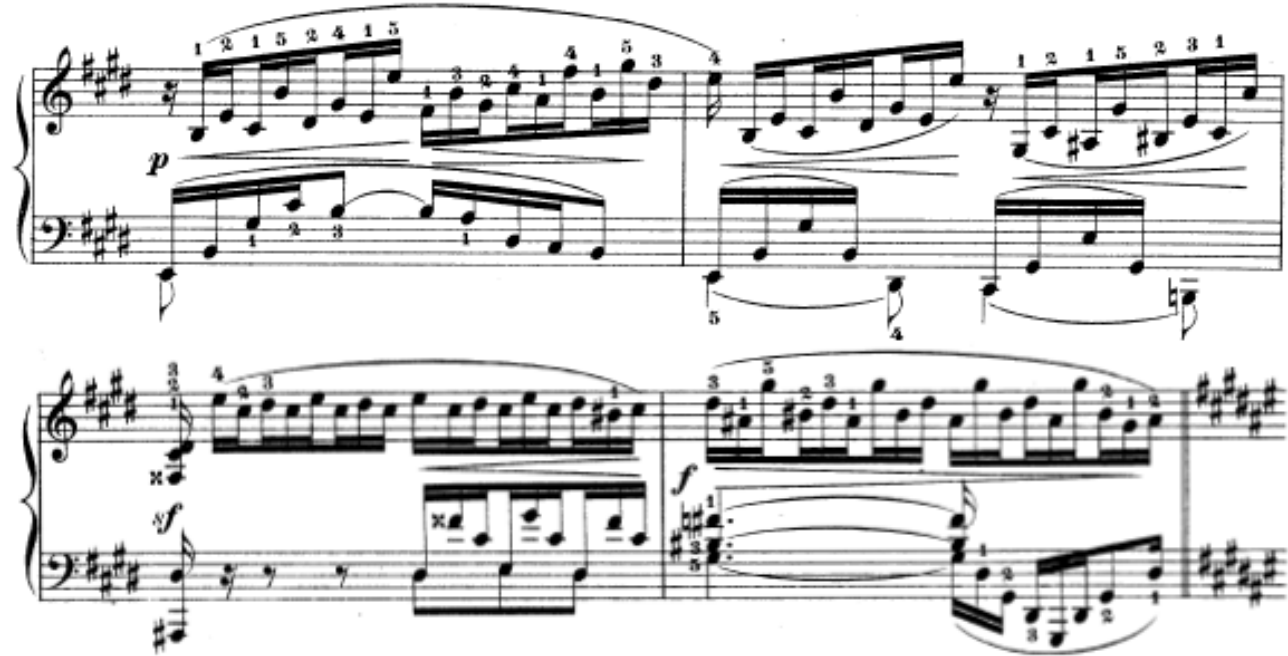

شكل رقم (3) يوضح الجزء الأول من القسم B من م (9): م(12) 
• الجزء الثاني: من م (13): م (15) وهو في سلم فا\#/ك، ويستمر على اعتماد نفس
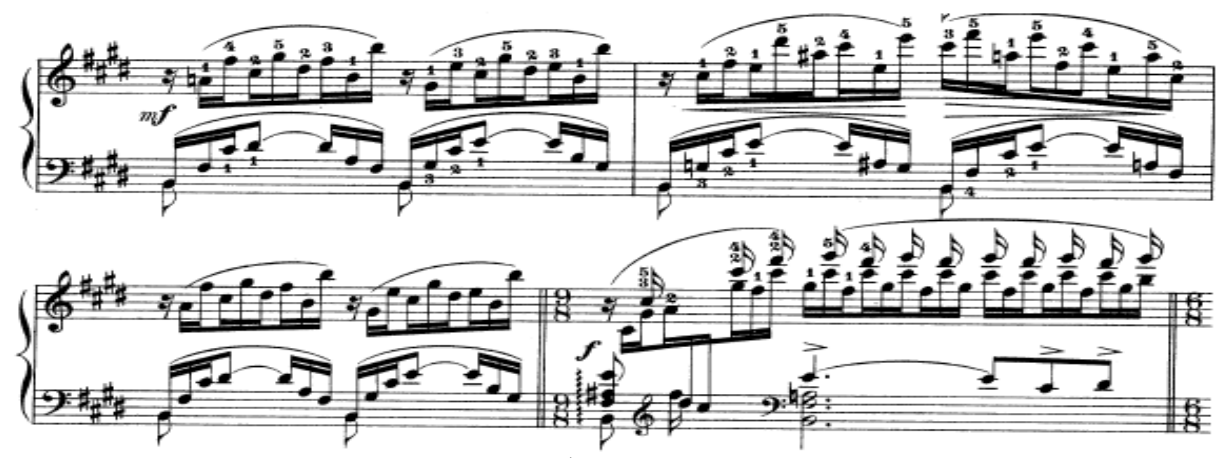

شكل رقم (4) يوضح الجزء الثاني: من م (13): م (15)

النموذج اللحني مع مصاحبة هارمونية تقوم على الأربيجات في اليد اليسرى.

وصلة لحنية: في م (16) باستعمال نفس النموذج الإيقاعي ومصاحبة هارمونية رأسية

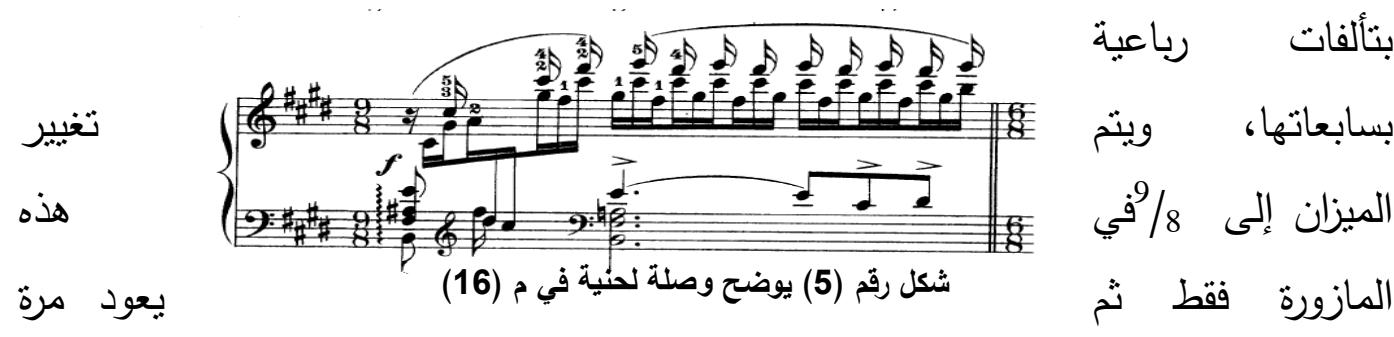

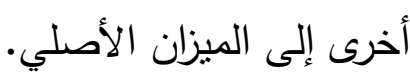

الجزء الثالث: من م (17): م (19) يتميز بلحن هابط في السوبرانو مع استمرار اعتماده على النموذج الإيقاعي المسيطر وعودة المصاحبة إلى أربيجية والتألفات رباعية بسابعتها. 

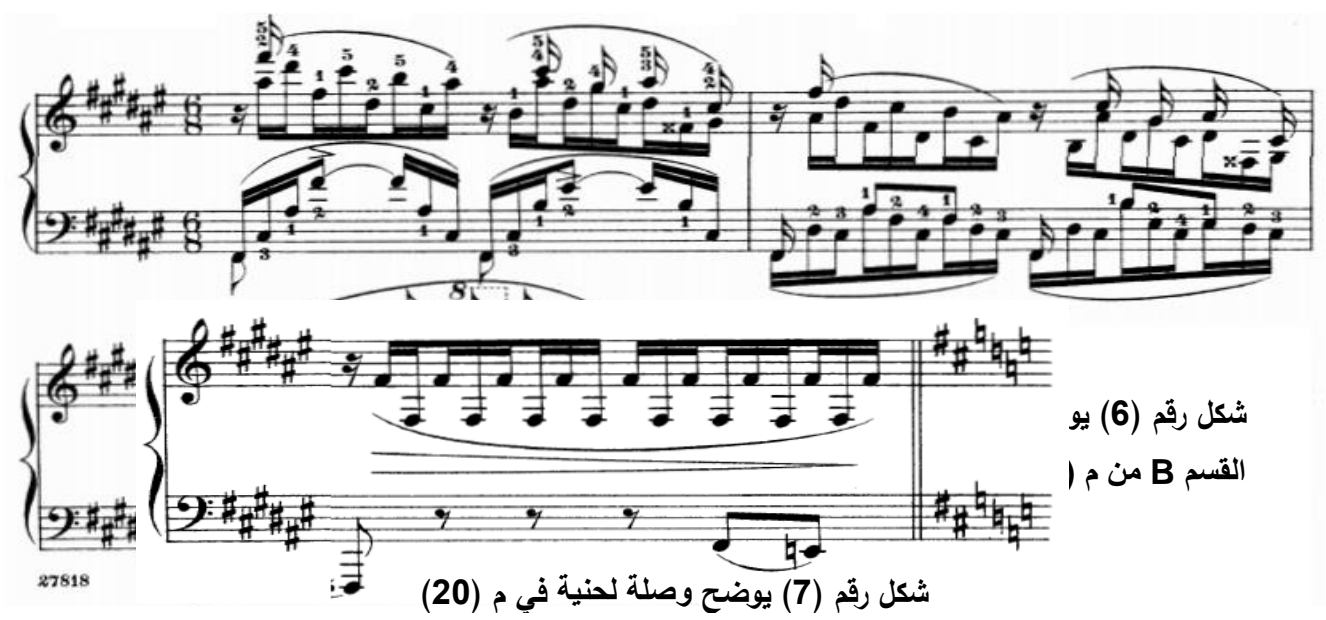

وصلة لحنية في م (20) على نغمة واحدة وأوكتافها في السوبرانو تمهيداً لتغيير السلم في إعادة هذا القسم، وهي عبارة عن صياغة بوليفونية على شكل نغمات منفرطة.

\section{التحليل الهارموني للقسم B:}

يستخدم المؤلف مصاحبة هارمونية تعتمد على نموذج إيقاعي في السوبرانو وأيضاً في الباص تقوم على الأربيجات في البد اليسرى، مع استخدام رأسية بتألفات رباعية بسابعاتها. إعادة قسم B: من م(21): م(32) مع تغيير السلم المستخدم في البداية حتى م(24) ليصبح سلم ري/ك ويكون اللحن عبارة عن تصوير لقسم B على بعد ثالثة كبيرة هابطة، ثم تغيير السلم مرة أخرى من م(25) إلى سلم مي/ك.

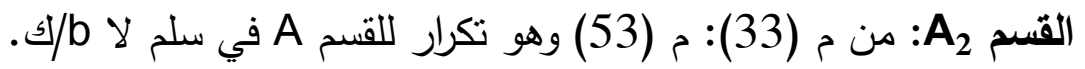
وصلة لحنية: من م (41): م (44) وهي عبارة عن صياغة لحنية بوليفونية تكرر في مادي مولي اللحن تعتمد على نفس النموذج السائد في البد اليمنى ونغمات منفرطة متغيرة في السوبرانو مع مسافات هارمونية رأسية مصاحبة في اليد اليسرى تقوم بعمل باص أرضية لوذه الوصلة. 

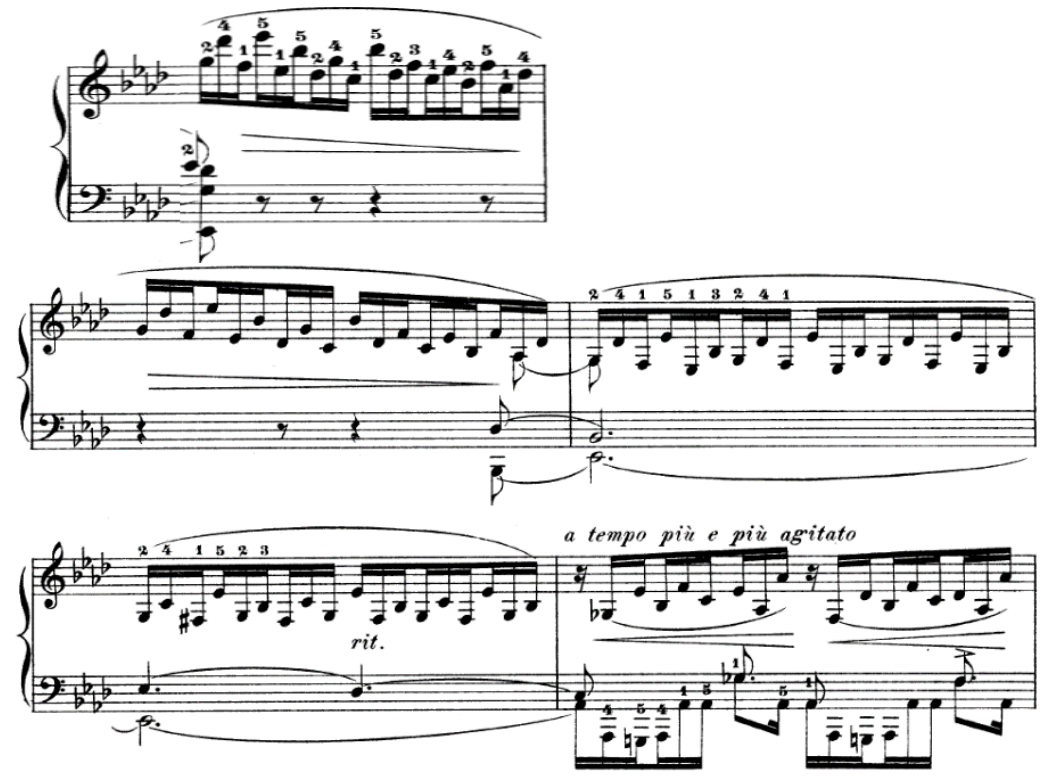

شكل رقم (8) يوضح وصلة لحنية: من م (41): م (44)

• كودا Coda : من م(54) : م(58) معتمدة على النموذج السائد للمقطوعة مقسم ما بين اليد اليمنى واليسرى في أول مازورة ، ثم تآلفات هارمونية بسابعاتها رأسية في اليدين من م(55) : م(56)، لتختتم الكودا في آخر مازورتين باستمرار التآلفات الهارمونية في اليد اليمنى مع مصاحبة أربيجية صاعدة حتى نهاية المقطوعة وققلة تامة في سلم لام/bك . 
مجلة البحوث في مجالات التربية النوعية
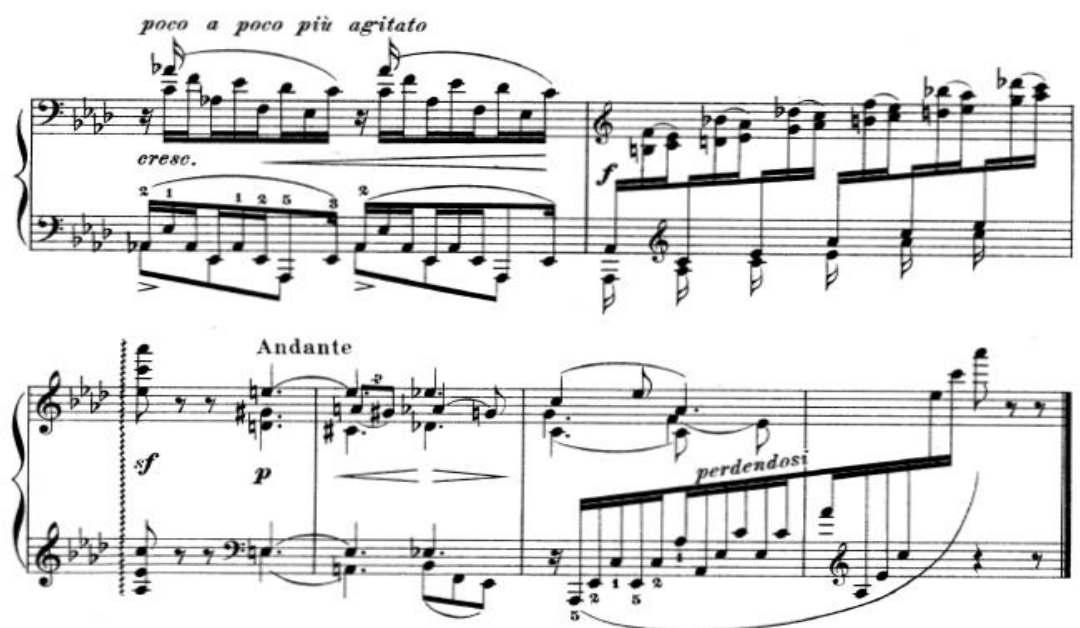

شكل رقم (9) يوضح كودا Coda : من م(54) : م (58)

الصعويات والمشاكل التكنيكية والإشثادات العزفية المقترحة للتفلب عليها للاراسات:

$$
\text { > الصعوية الأولى: تأخير التبر في اليد اليمنى في م 1، م5 }
$$

صياغة لحنية بدأت بتأخير النبر حيث بدأت بضغط قوي على النبر الثاني واستخدام الرباط اللحني والزمني تؤدى باليد اليمنى تصاحبها نغمات بوليفونية والثكل التالي ذلك: يوضح
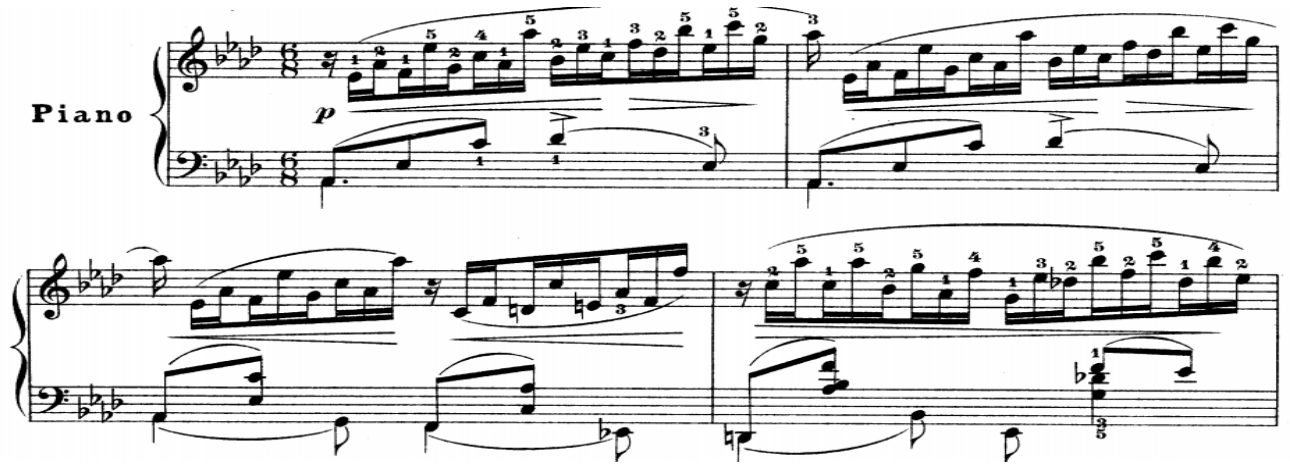

شكل رقم (10) يوضح تأخير النبر في اليد اليمنى في م 1، م4

متطلبات الأداء:

التدريب على أداء الضغوط المطلوبة في أماكنها مع الحفاظ على أداء الرباط اللحني والزمني في كلاً من اليدين والتدريب على التآزر بين كلاً من اليدين للحفاظ على التوازن الطبيعي للميزان وتقترح الباحثة التمرين التالي: 


\section{تمرين مقترح رقم 1:}

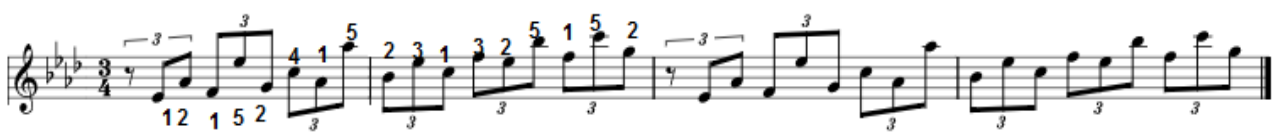

شكل رقم (11) يوضح تمرين مقترح للتبريب على تأخير النبر في اليد اليمنى في م 1

\section{الإرشادات العزفية:}

1. دراسـة قبليـة للمدونـة يـتم فيهـا التعـرف على مكونـات المدونـة مـن الناحيـة النغميـة

$$
\text { والإيقاعية. }
$$

2. يتم التدريب على أداء السينكوب بعيدا عن آلة البيانو وذلك بالنقر لضبط الوحدة

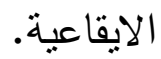
3. أداء السينكوب بمفردة دون الرباط الزمنى ثم إضافة الرباط الزمنى بعد ذلك 4. إظهار الضغوط الإيقاعية المطلوبة في أماكنها الصحيحة. 5. يتم التدريب على قراءة المدونة صولفائيا موضحا أماكن النبر القوى في القراءة. 6. يراعى أن يكون تدريب الأصابع وفق الترقيم المدون في المدونة الموسيقية. 7. يراعي أداء الصياغة اللحنية وفق اصطلاح التلوين الصوتي. 8. التدريب ببطء على البيانو وذللك لضبط الزمن. 9. أداء السينكوب بمفردة دون الرباط الزمنى ثم إضافة الرباط الزمنى بعد ذلك لهن > الصعوية الثانية: نغمات منفرطة تؤدى باليد اليسرى في م 34

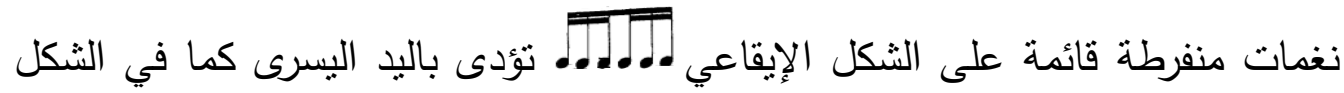
التالي:

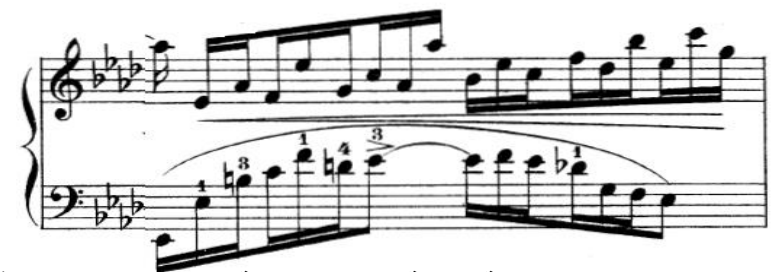

شكل رقم (12) يوضح الصعوبة الثانية نغمات منفرطة تؤدى باليد اليسرى في م 34

متطلبات الأداء: 
يتطلب الأداء للحركة العزفيـة القائمسة على نغمات منفرطة أن تأتى الحركة العزفية في تسلسل ورقة وبقوة لمس واحدة للنغمات ولإتقان ذللك تقترح الباحثة يتم التدريب على النحو

التالي:

\section{تمرين مقترح رقم 1}

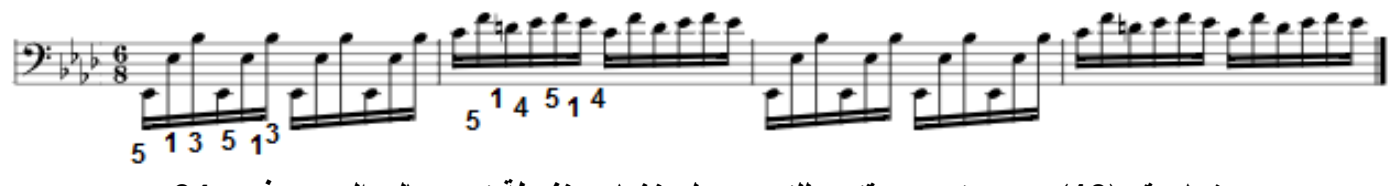

شكل رقم (13) يوضح تمرين مقترح للتدريب على نغمات منفرطة تؤدى باليد اليسرى في م 34

\section{الإشثادات العزفية:}

1. ان تؤدى بأسلوب الحركة الدائرية بمساعدة الساعد والرسغ.

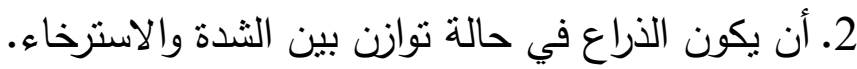
3. الالنزام بترقيم الاصابع المدون بأسفل النغمات.

4. أن تؤدى الحركة العزفية فوق القوس اللحني المتند فوق أربع نغمات الذى يتطلب العزف بوزن ثقل الذراع دون مبالغة بالنزول بالرسـ قليلا الى اسفل ثم تتوالى درجات التآلف بخفة وارتفاع الرسغ قليلا لأعلى. 5. أن تؤدى الحركة العزفية ببطيء ثم التدرج في سرعتها بعد الإتقان. > الصعوية الثالثة: صياغة لحنية متعددة الأسطر اللحنية في م 28 جاءت الصياغة على فكرة البوليفونية الهوموفونية لتعدد الأسطر اللحنية ثلاثة أو أربعة أسطر كما في الثكل التالي: - 20 


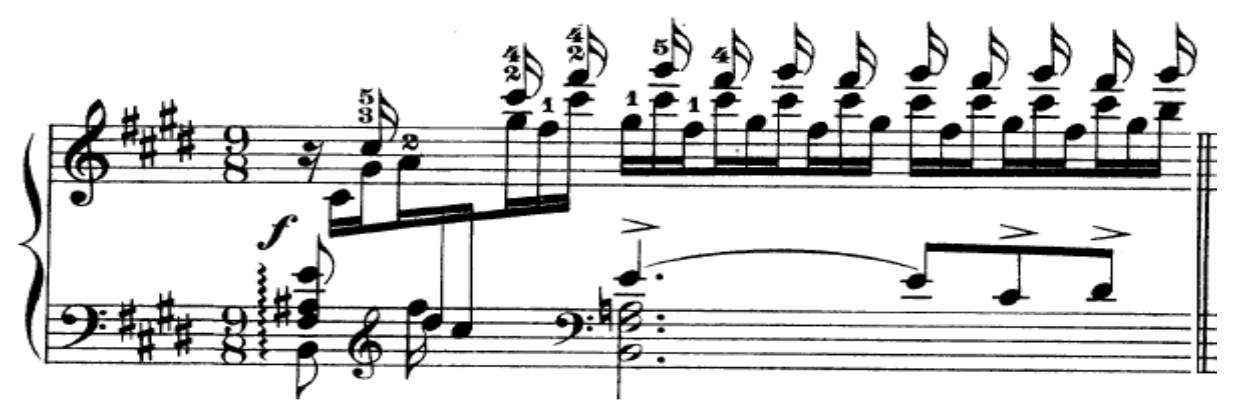

شكل رقم (14) يوضح الصعوبة الثالثة صياغة لحنية متعددة الأسطر اللحنية في م 28

• متطلبات الأداءء:

تدريب لكل يد على حده على الصياغة الموسيقية الاعتبارية لها كخطوة أولى في التعلم ويراعى أن تكون اصابع اليد قربية من لوحة المفاتيح أثناء الأداء وأن تكون قوة اللمس منساوية بكافة الأصابع المستخدمة.

$$
\text { الإرشادات العزفية: }
$$

1. التعرف على مكونات المدونة الموسيقية قبل التدريب الفعلي على لوحة المفاتيح. 2. الجمع بين اليدين مع الحرص على اظهرا الثخصية الاعتبارية لكل خط لحن دون طغيان أخد الخطوط على الآخر. 3. يراعى أن تكون الترجمـة الفعليـة لمكونـات المدونـة بدقة ويوكن التدريب يكون في التي

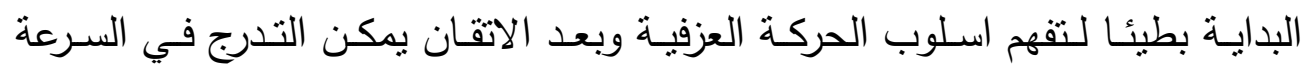
للوصول الى السرعة المطلوبة.

> الصعوية الرابعة: خطين لحنيين متثابهين ايقاعيا مختلفين نغميا في م 18

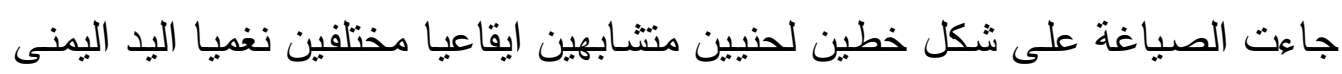

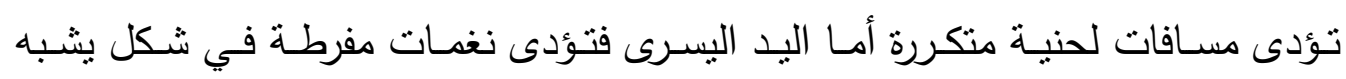
السيكوانس كما في الثكل التالي:

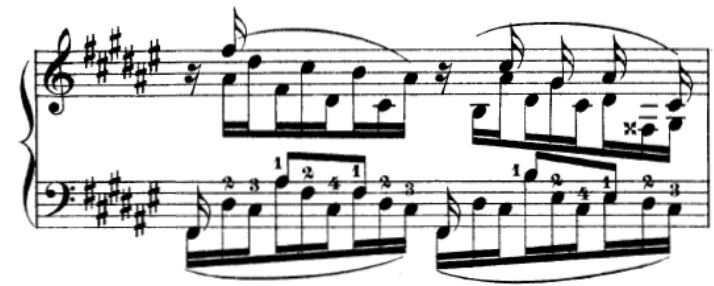

شكل رقم (15) يوضح الصعوبة الرابعة خطين لحنيين متثابهين ايقاعيا مختلفين نغيا في م 18 
- التعرف على مكونات المدونة الموسيقية نغميا وايقاعيا. - أداء الصياغة اللحنية بترابط وفق الأقواس اللحنية فوق النغمات. - إظهار الشخصية الاعتبارية لكل خط لحنى.

$$
\text { • الإرشادات العزفية: }
$$

1. الالتزام بأرقام الأصسابع المدونة في المدونة الموسيقية. 2. أن يراعى اسلوب أداء القوس اللحني فوق ثمان نغمات. 3. عزف النغمات المنفرطة في اليد اليسرى باستخدام الحركة الدائرية من الساعد والرسغ بمساعدة الاصابع على أداء الحركة العزفية.

4. ان تكون اصابع اليد في حالة استدارة لنتساوى النغمات الهارمونية في قوة الصوت. 5. العزف في البدايـة ببطيء مــع التدرج في السـرعة للوصـول الى السـرعة الأدائيـة المناسبة.

\section{> الصعوية الخامسة: نغمات منفرطة يعقبها تآلف في م 37} جاءت الصياغة على شكل نغمات منفرطة في اليد اليمنى يعقبها تآلف لهذه النغمات المنفرطة كما في الثكل التالي:

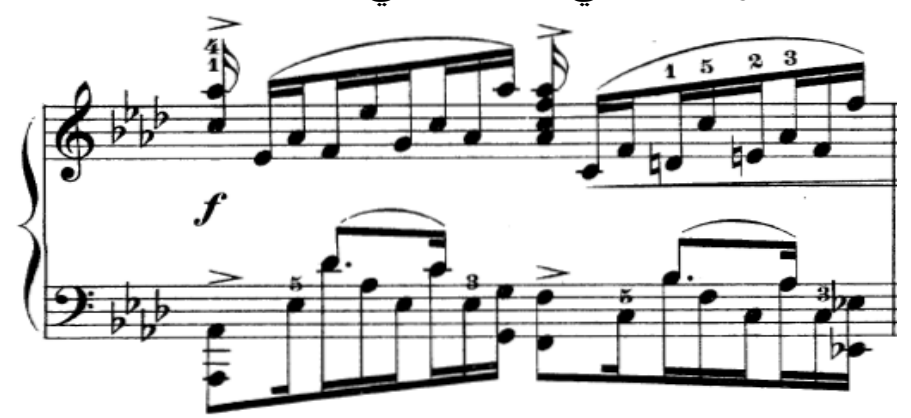

شكل رقم (16) يوضح الصعوبة الخامسة نغمات منفرطة يعقبها تآلف في م 37

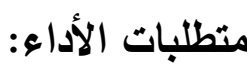


يتطلب أن تصدر أصوات التآلف متكاملة بعد أدائها منفرطة ويكون الأداء بوزن ثقل الذراع وبمرونة دون شد عضلي، مع ابراز الضغط النقيل فوق النغمات ولإتقان الحركة

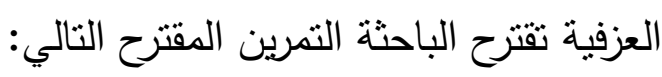

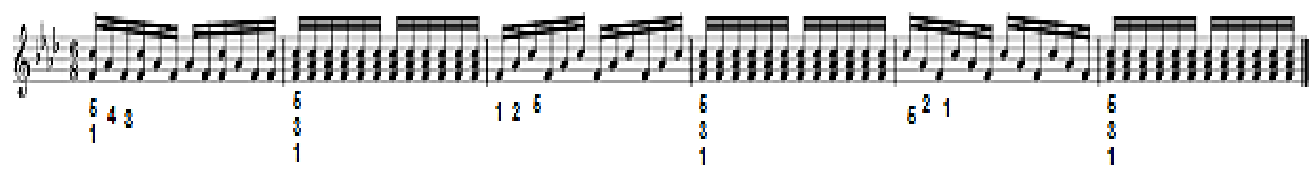

شكل رقم (17) يوضح تمرين مقترح للتظلب على صعوبة أداء نغمات منفرطة يعقبها

\section{الإرشادات العزفية:}

1. التعرف على مكونات الصياغة اللحنية للمدونة الموسيقية من الناحية النغية والايقاعية.

2. يراعى ان تأنى الحركة العزفية للمدونة ببطيء لإتقان اسلوب الحركة الأدائية للصياغة.

3. أن يكون الذراع حراً غير مقيدا عضليا أثناء أداء الحركة العزفية وأن تكون أصابع اليد قريبة من لوحة المفاتيح وفى حالة استدارة حتى تصدر الأصوات بقوة اللمس عليز متساوبة. 4. أن تؤدى الحركة العزفية بتدريب اليدين على كل سطر لحنى للتعرف على مكوناته وبعد اتقانه يمكن جمع اليدين معاً. 5. تبدأ الحركة العزفية بوزن ثقل الذراع ثم تتعاقب النغمات من خلا الص اصابع اليدين التي يجب ان تكون مرنة دون شد أو تقلص عضلي بحيث يكون الذراع والاصابع واليدين في حالة توازن بين الثد والاسترخاء اثثاء اداء الحركة العزفية. 6. لا يتم التدرج في السرعة إلا بعد اتقان كل خطوة سابقة. > الصعوية السادسة: تقنية العزف أوكتاف أعلى المنطقة الصوتية باستخدام علامة لإنة

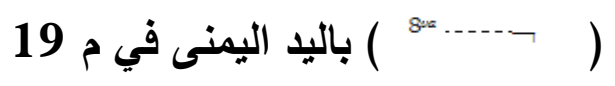




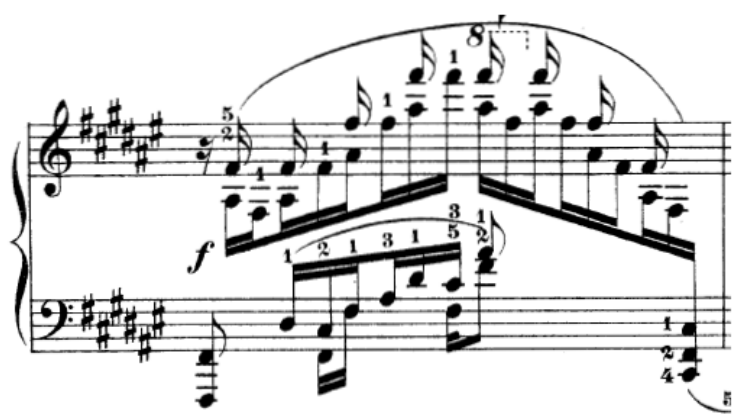

شكل رقم (18) يوضح الصعوبة السادسة تقتية العزف أوكتاف أعلى المنطقة الصوتية في اليد اليمنى في م 19

$$
\text { الارشادات العزفية: }
$$

1. تدريب اليد على الانتقال السريع للمنطقة الصوتية وإدراك المسافات بين آخر نغمة والتي تليها في المنطقة الصوتية الأعلى. 2. تدريب العين لتسبق الوقوع على مكان النغمة بجانب القراءة المتأنية للنغمات.

> الصعوية السابعة: أداء اليدين لحلية الأربيجيو في م 55

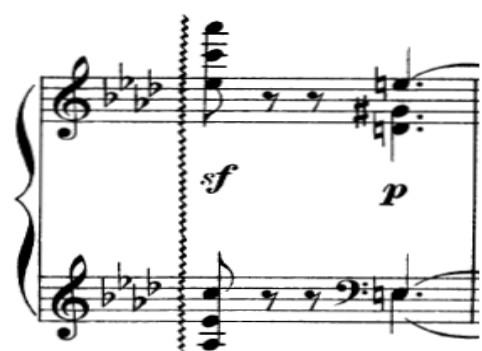

شكل رقم (19) يوضح الصعوبة السابعة أداء اليدين لحلية الأربيجيو في م 55

$$
\text { متطلبات الأداء: }
$$

- تؤدى اليد اليمنى واليسرى ايقاع الكروش باستخدام حلية الاربيجيو - تقترح الباحثة استخدام البدال في أداء الحلية. - - تقتزح الباحثة التمرين التالي لكيفية الأداء. 
مجلة البحوث في مجالات التربية النوعية

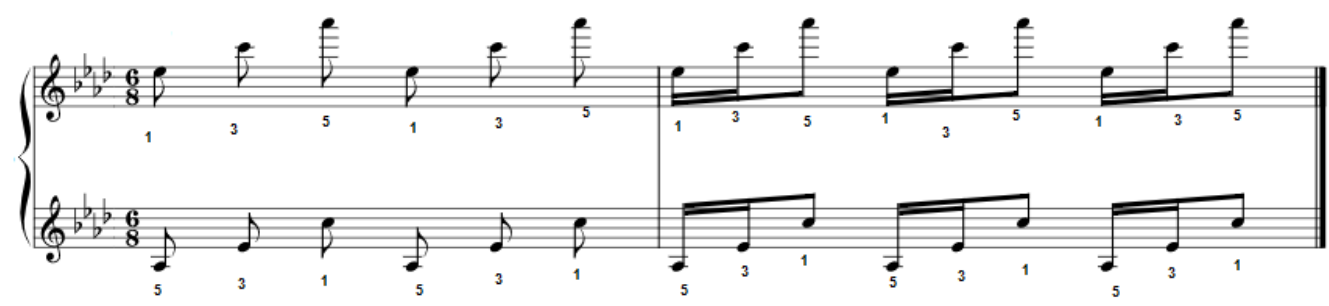

شكل رقم (20) يوضح تمرين مقترح لاداء اليدين لحليه الاربيجيو في م 55

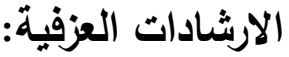

1. يجب ان يكون العزف من النغمة الأغلظ الى الاحد.

2. يراعى الدارس عند ادائه لحلية الاربيجيو ان تكون الحركة مرنة وسريعة ويتم التركيز

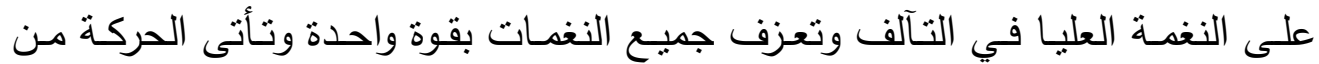
الأصابع والرسن معا بمساعدة الذراع. 3. يراعى التدريب وسرعة الانتقال في التآلف. 4. مراعاة الالتزام بأرقام الأصابع المقترحة من الباحثة. لالهن. > الصعوية الثامنة: أداء التآلفات المنفرطة في اليد اليسرى في م 29

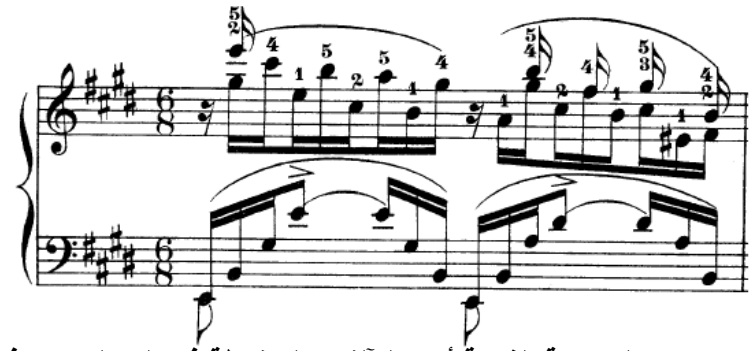

شكل رقم (21) يوضح الصعوبة الثامنة أداء التآلفات المنفرطة في اليد اليسرى في م 29

متطلبات الأداء:

يتطلب أدائها الالتزام بترقيم الأصـابع المدون جزئياً واستعداد اليد بدون شد لأداء

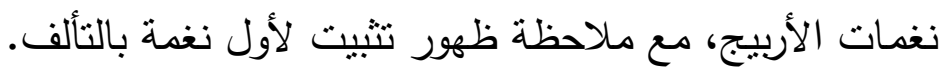
الارشادات العزفية: 1. يراعى ان تأتى الحركة العزفية للنغمات المنفرطة باستخدام أسلوب الحركة الدائرية للرسغ والساعد لمساعدة الأصابع لعزف النغمات. 
2. يراعى ان تكون أصابع اليد في حالة استدارة حتى يمكن أداء النغمات المنفرطة

بقوة لمس واحدة.

> الصعوية التاسعة: صعوية أداء تآلف ثلاثي ذو مسافات واسعة في اليد اليسرى

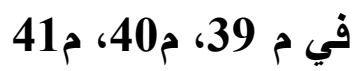

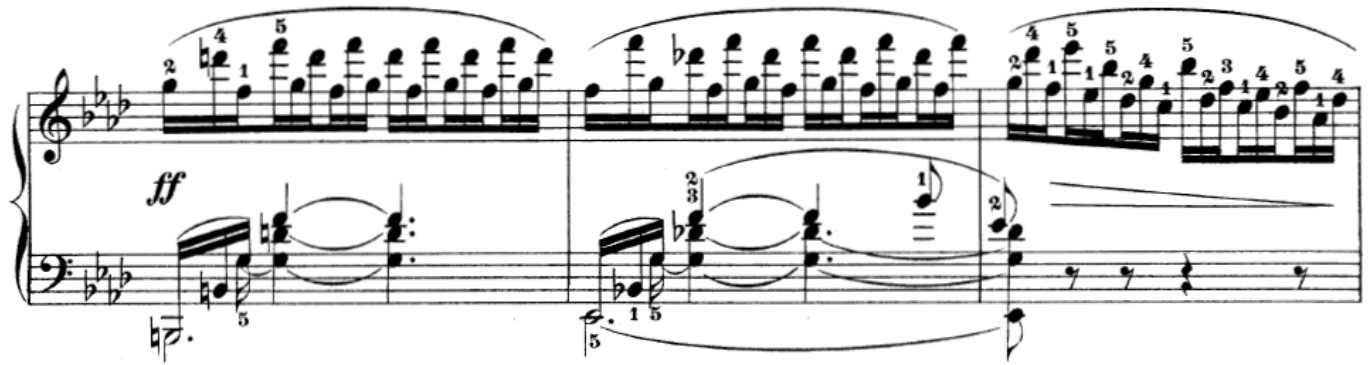

شكل رقم (22) يوضح الصعوية التاسعة أداء تالف ثُلاثي ذو مساقات واسعة في اليد اليسرى في م 39، م40، م41

متطلبات الأداء:

- - تقترح الباحثة لأداء التآلف ذو المسافات الواسعة في اليد اليسرى أن تؤدى بطريقة

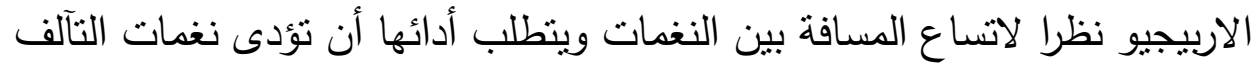

$$
\text { بسرعة نغمة تلو الأخرى. }
$$

- تقترح الباحثة التدريب على التمرين الآتي:

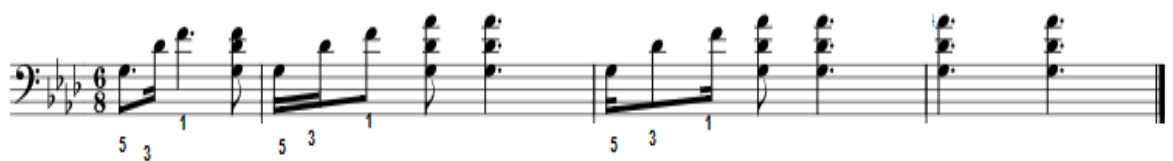

شكل رقم (23) يوضح الصعوية التاسعة أداء تآلف ثلاثي ذو مسافات وإسعة في اليد اليسرى في م 39، م0، م41

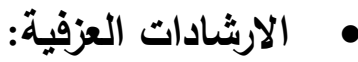

1. يجب ان يكون العزف من النغمة الأغلظ الى الاحد.

2. يراعى الدارس عند أدائه للتآّف ان تكون الحركة مرنة وسريعة وينت التركيز على التى

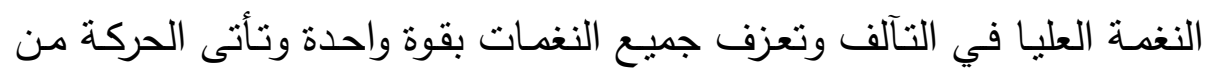
الأصسابع والرسغ معا بمساعدة الذراع. 3. يراعى التدريب وسرعة الانتقال في التآلف. 
> الصـوية العاشـرة: أداع نغمـة ممتدة في اليد اليسـرى يتبعها نغمـات لحنيـة صـاعدة

$$
\text { منفردة في م } 7
$$

\section{•متطلبات الأداء:}

يراعى التدريب أولا على عزف الصوت الممتد بمفردة ثم إضافة النغمات اللحنية المنفردة مـع ضـرورة استخدام البدال عند أداء الصـوت الممتد للحفاظ على استمرار الرنين مـع

$$
\text { الالتزام بأرقام الأصابع المقترحة }
$$

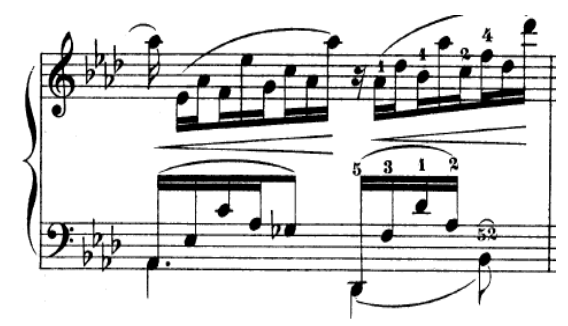

شكل رقم (24) يوضح الصعوية العاشرة أداع نغمة ممتدة في اليد اليسرى يتبعها نغمات لحنية صاعدة منفردة في م 7

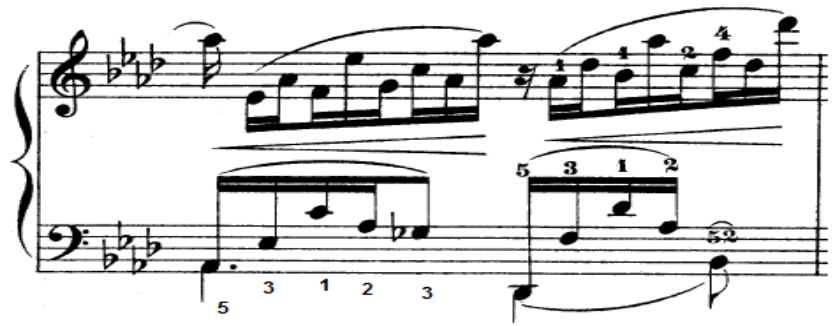

شكل رقم (25) يوضح الترقيم المقترح من قبل الباحثة

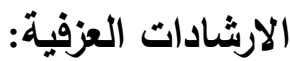

1. التعرف على مكونات المدونة من الناحية النغية والايقاعية.

2. يراعى أن تكون اصابع اليد اليسرى في أداء الطابع التكنيكي في الصياغة في حالة التيهاعه استدارة ليتساوى الأصبع في قوة لمس النغمات. 
3. يراعى الدقة في اداء النغمات المنفرطة على لوحة المفاتيح. 4. يراعى أداء الاكسنت من خلا وزن نقل الذراع مع استخدام الحركة الدائرية من الساعد والرسغ في أداء الضغط.

5. مراعاة أداء النغمة الممتدة من خلا لم استخدام البدال المستمر . الصعوية الحادية عشر: أداء تآلف خماسي يتبعه نغمات سلمية هابطة باليد اليمنى في م 28

متطلبات الأداء:

يراعى ان يكون العزف بانسيابية وإنقان مترابط ويجب أن تكون أصسابع اليد قريبة من لوحة المفاتيح ليسمع الثكل الإيقاعي وكأنه يد واحدة.

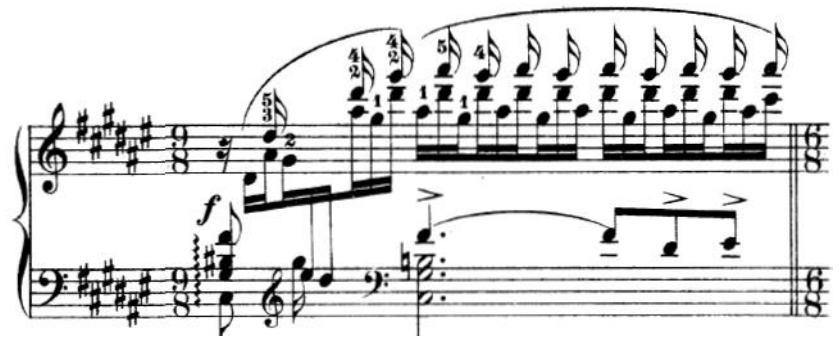

شكل رقم (26) يوضح الصعوبة الحادية عشر أداء تآلف خماسي يتبعه نغمات سلمية هابطة باليد اليمنى في م 28

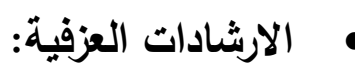

1. مراعاة العزف ببطيء لليدين والتعرف على النغمات لكل تآلف وأوكتاف على حدة. 2. عند عزف التآلفات الهارمونية والأوكتافات مراعاة أداء جميع النغمات بقوة واحدة

$$
\text { مع عدم شد اليد وبضغط متساوي. }
$$

\section{الصياغة الهارمونية:}

جاءت الصياغة الهارمونية في بداية الدراسات على هيئة فرد نغمات التآلفات الهارمونية بالتبادل مع هارمونيات رأسية، ثم تغيير المصاحبة لتصبح على هيئة أربيجات مع تضعيف العلامات الزمنية الإيقاعية، ويستمر المؤلف في اعتماده على نفس النموذج 
الإيقاعي في السوبرانو والباص، تقوم على الأربيجات في اليد اليسرى، وهارمونية رأسية بتألفات رباعية بسابعاتها، ثم العودة إلى استخدام الأربيجية والتألفات رباعية بسابعاتها باستمرار التآلفات الهارمونية في اليد اليمنى مع مصاحبة أربيجية صاعدة وفي اليد اليسرى على باص أرضية، واستمرار التآلفات الهارمونية في اليد اليمنى مع مصاحبة

$$
\begin{aligned}
& \text { أربيجية صاعدة حتى نهاية المقطوعة } \\
& \text { التلوين الصوتي: }
\end{aligned}
$$

جاءت الدراسات بطابع تكنيكي لحنى وادائها سريع دون توقف وذللك لأن المؤلف استخدم مصطلح (Allegro ma non troppo) وقد اشتملت على المصطلحات التالية: مصطلح(p) ويعنى اداء النغمات بأسلوب خافت وجاء في الموازير 1: 10 ، والموازير 21، 22 ، مصطلح(mf) ويعنى الاداء النغمات بصوت منوسط القوة في الموازير من 13 : 18 ، مصطلح(f) وبعنى اداء النغمات بأسلوب قوى في الموازير 23 ، 24، ومن م28الى م38 ، م 47 الى م 49 ، مصطلح(ff) ويعنى اداء النغمات بأسلوب قوى جدا في الموازير 39 : 46 ، مصطلح ( ר...................... وهو يعنى أداء الجملة على أوكتاف أعلى من الأصوات المدونة وهى اختصار لمصطلح (ottava) كما في الموازي م 19 ى، م 48 ، م49 مصطلح(cresc) ويعنى ازدياد شدة الصوت تدريجيا كما في م 21، مصطلح (A tempo) وهو يعنى العودة الي الزمن الأصلي كما في م 51، مصطلح (poco a poco più agitato) ويعنى الأداء بتدرج أكثر حيوية ، مصطلح ( ) مهنى poco ritard

\section{التدوين الموسبقى:}

جاء التدوين الموسيقى في الصياغة الموسيقية للدراسات منوافقا مع الصياغة اللحنية حيث استخدم في البداية مدرجي مفتاحي صول وفا ثم أنتقل الى مدرجي صول وصول 
ثم انتقل الى مدرجي صول وفا ثم أنتقل الى مدرجي صول وصول وانتقل الى مدرجي مفتاحي صول وفا واختتم بمدرجي مفتاحي صول وصول.

البدال: لم يحدد في الدراسـات أسلوب استخدام البدال، وتركه لحرية العازف وتقترح

$$
\text { يمكن حصرها فيما يلي: البحتث: البتخدام البدال في أداء الدراسات. }
$$

1. جاءت الدراسات في صياغة هوموفونية، مع تغيير الميزان داخل القالب،

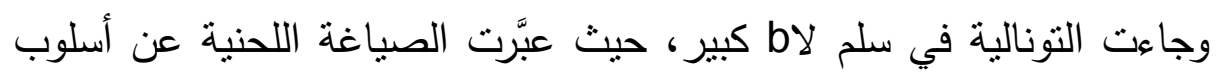
المؤلف المعبر عن المهارة العزفية على آلة البيانو، والتمكن في استخدام

$$
\text { الموارد. }
$$

2. جاءت الإيقاعات المنتظمة، وغير المنتظمة، والمقابلات الإيقاعية. 3. من خلال التحليل العزفي من توضيح الخصائص الفنية لدراسات البيانو عند

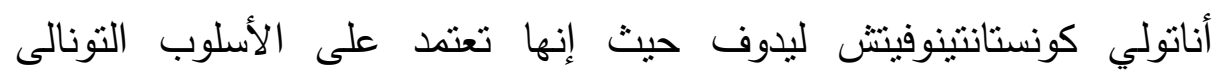
والأسلوب الكروماتيكى وهي ما تميز به اسلوبه في التأليف الموسيقى في عصره

$$
\text { أسلوب. }
$$

4. تتوعت الاصطلاحات التعبيرية داخل قالب الدراسات.

$$
\text { 5. لم يستخدم المؤلف البدال. }
$$

6. اقتصرت الحليات على حلية الاربيجيوا.

$$
\text { توصيات البحث: }
$$

في ضوء ما تم توصلت إليه من نتائج يوصى البحث بما يلي:

1. الاهتمام بدراسة المؤلفات الموسيقية للمؤلف الموسيقي الأمريكي أناتولي

$$
\text { كونستانتينوفيتش ليدوف. }
$$

2. الاستفادة من إدراج دراسات أناتولي كونستانتينوفينش ليدوف في برامج تدريس

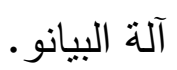


3. توفير المدونات والتسجيلات الموسيقية للمؤلفات العالمية، وخاصا أعمال المؤلف

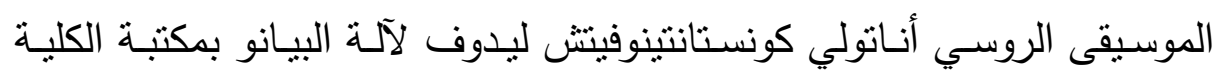

حتي يتسنى للاراسين فرصة الاستماع الي هذه الأعمال القيمة.

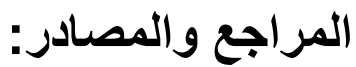

1. 2.آمال صادق، فؤاد أبو حطب (1991): "مناهج البحث وطرق التحليل الإحصائي"، مكتبة

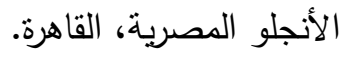

2. أحمد يحيى عبد العزيز (2019): مازوركا البيانو عند أناتولي ليادوف دراسة تحليلية عزفية،

بحث منشور، مجلة علوم وفنون الموسيقى، كلية التربية الموسيقية، المجلد الواحد والاربعون.

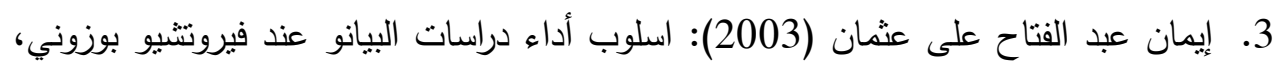

رسالة ماجستير ، كلية التربية الموسيقية، جامعة حلوان اندان، القاهرة.

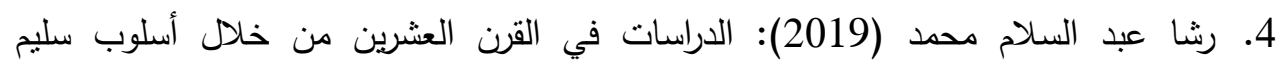

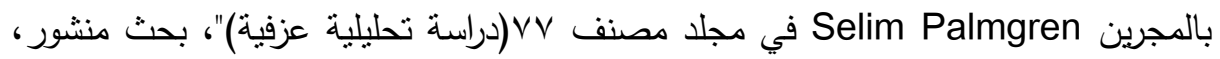

مجلة علوم وفنون الموسيقى، المجلد الاربعون، كلية التربية الموسيقية، جامعة حلوان.

5. سمحه الخولي (1992): القومية في الموسيقي العشرين، المجلس الوطني للثقافة والفنون

والآداب الكويت.

6. يونس محمود محمد بدر (2000): أسلوب أداء دراسات البيانو عند سكريابين "، رسالة

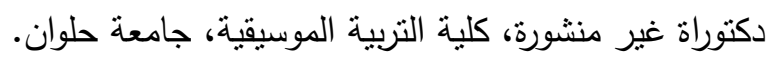

7. https://ar.vvikipedla.com/wiki/anatoly_lyadov

8. https://imslp.org/wiki/Category:Lyadov,_Anatoly

9. JI Won Baik:" Gyorgy Ligeti's Piano Etudes, A Polyrhythmic Study", Florida State University, College of Music, for the degree of Doctor of Mudic ‘Summer Semewter, 2009

10. Michae L Kennedy: The concise oxford dictionary of music 3 thewier.

11. Thompson, Virgil: American Music Since 1910, Weidenfeld and Nicgolson, London 1971.

12. Willi Apel: Harvard Dictionary of Music, Harvard college copy right 121 printing, U.S.A .1979. 


\section{ملخص البحث}

دراسة تحليلية لأسلوب أداء قالب الدراسات عند أناتولي كونستانتينوفيتش ليدوف

بدأت الموسيقى الروسية من خلا الإنشاد الديني والترانيم الكنسية، ومع بدايات القرن الخامس عشر انتقل بعض الموسيقيون الروس للاستفادة من بعض الدول الرائدة موسيقيا منل إيطاليا وفرنسا، أما في بداية القرن التاسع عشر كان الثعب الروسي يختص بموسيقى وألحان واناشيد واغان شعبية ورقصات فلكلورية، وفى بدايات القرن العشرين اندلعت الثورة في روسيا وتغيرت السياسة الداخلية والنظم الاجتماعية التي انعكست على التقافة والموسيقى، وكان من الضروري ابداع موسيقى تساير المجتمع الجديد بشرط أن تكون نابعة من التقاليد والتراث الروسي، ومن أهم المؤلفين الموسيقيين الذين اشتهروا Anatoly بموسيقاهم المؤلف الموسيقى أناتولي كونستانتينوفينش ليدوف Konstantinovich Lyadov بالدقة والوضوح وتأثرها بالموسيقى الرومانتيكية والأغاني الثعبية الروسية الأمر الذى جعل الباحثة تفكر في تتاول مؤلفة (الدراسات) ذات المهارات التكنيكية بالدراسة الوصفية والتحليل وما اثتنمل عليها من تحليل نظري وعزفي وذللك بهدف استخراج التقنيات العزفية التي بنيت عليها، مع وضع الارشادات اللازمة للتغلب على الصعوبات التكنيكية والعزفية وذلك للأداء الجيد، حيث جاءت ابرز النتائج أنها جاءت في صياغة هوموفونية، مع تغيير الميزان داخل القالب، وجاءت التونالية في سلم لا كبير، كما جاءت الإيقاعات المنتظمة، وغير المنتظمة، والمقابلات الإيقاعية، واوصت الدراسة بالاهنمام بدراسة المؤلفات الموسيقية للمؤلف الموسيقي الأمريكي أنانولي كونستانتينوفينش ليدوف الاستفادة من إدراج دراسات أناتولي كونستانتينوفيتش ليدوف في برامج تدريس آلة 